\title{
Author Index (Volume 24)
}

Abbes, M. 1650014

Abd Elraheim, D. 1650021

Ahmadu, T. O. 1650012

Ahn, J. 1650007, 1650025

Amoabeng, K. O. 1630008

Anafi, F. O. 1650012

Aridhi, E. 1650014

Bouazza, A. 1630006

Byun, H. W. 1630009

Castro, L. F. N. 1650008

Cauret, O. 1650011

Cho, H. 1650005

Choi, J. M. 1630008

Choi, S.-H. 1650016

Choi, Y. U. 1650017

Chung, H. 1650016

Cuong, L. N. 1650004

da Silva, F. V. 1650024

Dall'Olio, R. 1650002

Dantas, T. S. S. 1650024

Das, R. K. 1630003

De Zen, D. 1650002

Diani, A. 1650002

Enteria, N. 1650023

Faizal, M. 1630006

Fatouh, M. 1650021

Fileti, A. M. F. 1650024

Folayan, C. O. 1650012

Franco, I. C. 1650024

Gonet, A. 1630001

Goossens, M. 1650011

Guo, X. 1650006
Hwang, S. 1650015

Hwang, Y. 1650001

Jeong, H. 1650016

Jeong, J. H. 1630002, 1650015

Jeon, S. H. 1650017

Jeon, S. W. 1630004

Joshi, D. 1650009

Kang, Y. T. $\quad 1630004,1650003$

Khan, A. A. 1650018

Khan, Md. I. H. 1630007

Kim, B. 1650001

Kim, D. H. 1630009

Kim, K.-Y. 1650018

Kim, M. S. 1650017

Kim, N.-H. 1650013, 1650020, 1650027

Kim, O. J. 1630009

Kim, S. Y. 1650007

Kim, Y. S. 1650016

Kim, Y. 1630004

Korti, A. I. N. 1650010

Kouropoulos, G. P. 1630005

Koury, R. N. N. 1650008

Kwon, Y.-I. $\quad 1650019,1650026$

Lee, H. 1650001

Lee, K. H. 1630009

Lin, X. 1650001

Machado, L. 1650008

Mahmoud, O. E. 1650021

Mami, A. 1650014

Marchio, D. 1650011

Masetto, F. 1650002
Nunes, R. O. 1650008

Oh, J.-T. 1650004

Pirompugd, W. 1650022

Radermacher, R. 1650001

Riviere, P. 1650011

Rosen, M. A. 1630001

Rossetto, L. 1650002

Sapinska-Sliwa, A. 1630001

Sarkar, J. 1650009

Sataki, A. 1650023

Seon, G. 1650025

Shi, Y. 1650006

Shin, Y. 1650005

Shon, B. H. 1630004

Singh, R. M. 1630006

Sliwa, T. 1630001

Song, C. H. 1630009

Song, S.-K. 1650016

Sur, A. 1630003

Teuillieres, C. 1650011

Tran, C. T. 1650011

Wongwises, S. 1650022

Yi, C. 1650016

Yoon, S. H. 1630009

Yoon, S. 1650003

Yoshino, H. 1650023

Yun, J. H. 1630002

Zhang, X. 1650006 